\title{
CONCEPÇÕES E PRÁTICAS DE GESTÃO DO CONHECIMENTO NA EDUCAÇÃO A DISTÂNCIA
}

LONDRINA/PR JULHO/2018

\author{
Dalila Gimenes da Cruz - UNOPAR - dalilagimenes@gmail.com \\ Tipo: Investigação Científica (IC) \\ Natureza: Relatório Final de Pesquisa \\ Categoria: Métodos e Tecnologias \\ Setor Educacional: EDUCAÇÃO SUPERIOR
}

\begin{abstract}
RESUMO
Este estudo aborda a possibilidade do uso de práticas de gestão do conhecimento, que em conjunto com as tecnologias de informação e comunicação, podem promover melhorias no desenvolvimento de projetos em educação a distância. A pesquisa teve como objetivo conhecer as concepções e práticas de gestão do conhecimento de coordenadores de curso de graduação que atuam na modalidade EaD, buscando identificar habilidades e competências diretivas orientadas para métodos de gestão do conhecimento, além de investigar como acontece a participação desses profissionais envolvidos no compartilhamento de informações em ambientes EaD. O estudo proposto foi desenvolvido a partir de uma pesquisa descritiva com abordagem qualitativa. A coleta de dados foi realizada por meio de entrevistas semiestruturadas, realizadas com coordenadores de cursos de graduação ofertados na modalidade EaD por uma instituição de ensino superior de atuação nacional. A partir das entrevistas foi possível verificar a identificação e relatos de experiências voltadas para processos de gestão do conhecimento por parte dos profissionais, indicando que métodos de GC estão sendo utilizados para desenvolvimento de atividades de gestão em educação a distância. No contexto de valorização da informação e do conhecimento, espera-se que a gestão do conhecimento possa atuar nos sistemas de educação a distância, visando contribuições efetivas nesse campo em expansão na sociedade contemporânea.
\end{abstract}

Palavras-chave: Gestão do Conhecimento. Educação a Distância. Tecnologias de Informação e Comunicação. 


\section{INTRODUÇÃo}

A busca da informação e do conhecimento está presente na vida dos indivíduos de forma muito natural, e através das tecnologias de informação e comunicação (TIC) 0 acesso torna-se cada vez mais presente. Esta realidade contribui para expandir o alcance ao conhecimento além das estruturas formais, abrindo muitas possibilidades de obter informação por meio de redes de comunicação e informação, favorecendo a construção de novos saberes.

Um dos sistemas em grande expansão nos últimos anos, apoiado pelas novas tecnologias, é o da Educação a Distância $(\mathrm{EaD})$, pois amplia muito a acessibilidade à informação e conhecimento em virtude da quebra de barreiras físicas.

Em contrapartida a esta disseminação ampliada da informação e as novas estratégias de aprendizagem que geram novos conhecimentos constantemente, através da EaD, percebe-se a necessidade do uso de modelos de gestão do conhecimento que possam auxiliar os processos de organização e promover melhorias nos sistemas de produção das organizações e instituições.

Com o crescimento da demanda por cursos oferecidos pela EaD, o aumento da concorrência e a competitividade do mercado, muitas instituições que trabalham com cursos nessa modalidade verificam a necessidade de melhoria de seus processos a partir do uso da gestão do conhecimento (GC).

A GC, com suas técnicas e ferramentas, é uma excelente alternativa para a busca de melhorias contínuas nos processos organizacionais de trabalho, como é o caso da EaD com seus processos complexos que necessitam estar em constante atualização para garantir que a produção esteja sempre adequada ao objetivo do projeto. Quanto melhor for a organização dos processos, pensando em termos de estrutura, reuso de informações, melhorias a partir de interações entre equipes e outras tantas variáveis, melhor será o resultado.

Este artigo expõe resultados parciais obtidos na pesquisa desenvolvida para a dissertação de mestrado intitulada "Práticas de Gestão do Conhecimento na Educação a Distância", desenvolvido por esta autora. Teve como objetivo geral conhecer concepções e práticas de GC utilizadas por coordenadores de cursos de graduação ofertados na modalidade EaD. Para tanto, foram definidos como objetivos específicos: a) identificar habilidades e competências orientadas para métodos de GC entre os coordenadores que atuam na modalidade $\mathrm{EaD}$; b) identificar métodos de GC nas 
práticas profissionais de coordenadores que atuam em EaD; c) evidenciar experiências vivenciadas por coordenadores com relação as práticas de GC em atuação profissional.

\section{GESTÃO DO CONHECIMENTO NA EDUCAÇÃO A DISTÂNCIA}

A sociedade contemporânea traz a necessidade de desenvolver novas maneiras de ensinar e aprender que priorizem formas diferentes de produzir, processar e disseminar o conhecimento. Nesse cenário, a EaD é vista como uma importante proposta metodológica que tem transformado a maneira de pensar a educação.

Segundo Moraes (2016), para construção de novos conhecimentos é preciso estabelecer modelos educacionais em que alunos e professores possam agir juntos na investigação, seleção e articulação de novas informações, que integradas a conhecimentos já adquiridos, possam gerar novos saberes.

Para atender a essas necessidades emergentes é fundamental a utilização de canais tecnológicos e humanos que viabilizem novas maneiras de ensinar e aprender, além de estruturas organizacionais complexas. Para que o ensino chegue ao aluno com a qualidade esperada, é desejável que haja um processo de promoção do conhecimento que tem início na definição de propostas de ensino, estabelecimento de diretrizes curriculares e desenvolvimento de conteúdos de qualidade. Um sistema de EaD que atenda a estes requisitos precisa ser formado por uma equipe de profissionais que se comprometam com o valor do conhecimento para a empresa e para a sociedade.

No entanto, a administração e o gerenciamento de conhecimentos não dizem respeito somente a exercer controle sobre o conhecimento dos indivíduos, mas principalmente controle sobre as situações em que o conhecimento é gerado, registrado, organizado, compartilhado, disseminado e utilizado no intuito de ter subsídios para melhores tomadas de decisão e adaptação aos ambientes desafiadores e mutáveis em que a organização atua (BARBOSA, 2008).

Nesse sentido, a GC cada vez mais se constitui em foco de análise e aplicação nas organizações. Atualmente sua relevância passa a ser inquestionável na gestão de instituições de ensino, exigindo uma nova postura com relação aos desafios contemporâneos. Para manterem-se competitivas e sustentáveis no mercado, as instituições precisam buscar, mediante mecanismos de gestão, promover estratégias que as auxiliem na criação, compartilhamento e disseminação de conhecimentos. Diante da importância do tema, é possível encontrar na literatura vários autores que conceituam a GC no âmbito organizacional. 
A GC parte do princípio de que a partir de análises de fatos ocorridos, é possível promover melhorias nos processos e tomadas de decisão das organizações. Nonaka e Takeuchi (1997) trazem em linhas gerais que a GC é como um processo, pelo qual as organizações buscam novas formas de criar e expandir o conhecimento. Para Davenport e Prusak (1998), a GC é um conjunto de ações que procura identificar, capturar, gerenciar e compartilhar as informações da organização.

Ao considerar a crescente competitividade imposta pela economia do conhecimento, Mattera (2014) complementa, definindo a GC como um processo de gestão que se realiza através da soma de metodologias e ferramentas, com o objetivo de estimular ambientes de aprendizagem e compartilhamento de informações que promovam maior eficiência organizacional, ampliando a capacidade competitiva das organizações.

As práticas de GC favorecem o aprendizado, potencializam a inovação e proporcionam avanços no conhecimento organizacional, garantindo para as empresas sustentabilidade e competitividade. Através da interação entre os membros da organização é possível estabelecer novas conexões e canais de compartilhamento que estimulam a criação de novos fluxos de informação organizacional. Mais do que compartilhar informações, ao compartilhar experiências, as pessoas estão atribuindo valor à informação e incorporando-as aos seus processos cognitivos, interpretando-as e transmitindo aquilo que é absorvido como novo conhecimento (MATTERA, 2014).

É possível encontrar a aplicação de práticas de compartilhamento de conhecimento em muitas organizações. No entanto, as empresas de modo geral, não conhecem ou não utilizam o termo "Gestão do Conhecimento" formalmente, mesmo fazendo uso de suas técnicas e ferramentas.

Verifica-se também diversidade de práticas de GC e cada organização deve identificar quais melhor se aplicam a sua realidade, pois diante das diversas práticas de compartilhamento do conhecimento descritas na literatura, divergentes em número e classificadas de acordo com diferentes dimensões, verifica-se a inexistência de uma lista unificada estabelecida por autores de referência na área (DOROW, 2017; MATTERA, 2014).

Para fins desta pesquisa, foram selecionadas dez práticas de GC, descritas na literatura, para nortear o desenvolvimento do estudo. Entre elas estão: brainstorming, lições aprendidas, narrativas, mapa do conhecimento, memória organizacional, comunidades de prática, fórum de discussão, localizador de especialistas, espaço virtual colaborativo e educação corporativa. 


\section{PROCEDIMENTOS METODOLÓGICOS}

O presente estudo consiste em uma pesquisa de natureza aplicada, com abordagens qualitativa e descritiva.

Como população a ser pesquisada, delimitou-se coordenadores de curso de graduação $\mathrm{EaD}$ que atuam em uma Universidade Privada de abrangência nacional. Considerando que essa instituição oferta 24 cursos de graduação na modalidade $\mathrm{EaD}$, a amostra representativa para esta pesquisa foi composta por seis profissionais que atuam na coordenação acadêmica desses cursos.

Como critério para a escolha dos participantes da pesquisa, aplicou-se a amostra intencional e não probabilística, por meio de indicações. Esta pesquisa teve uma abordagem qualitativa e consistiu na aplicação de entrevistas pré-agendadas, realizadas in loco, gravadas e posteriormente transcritas. Os gestores foram selecionados por indicação da Gerência Acadêmica de $\mathrm{EaD}$ da instituição para participarem das entrevistas. A intencionalidade da amostra visou garantir a escolha de profissionais que mais pudessem contribuir com o desenvolvimento da pesquisa, levando-se em consideração o tempo de experiência, vivência e envolvimento em atividades de gestão em EaD.

As entrevistas foram realizadas no mês de outubro de 2017 e tiveram como base um roteiro semiestruturado, composto por 10 questões, com o intuito de abordar concepções e práticas de GC em atuação profissional dos participantes.

Faz-se importante destacar que o objetivo desta pesquisa foi conhecer as concepções e práticas de Gestão do Conhecimento de coordenadores de curso que atuam na modalidade $\mathrm{EaD}$, partindo do seu ponto de vista pessoal e profissional. A relevância foi centrada nas experiências práticas profissionais e individuais vivenciadas por cada indivíduo participante da pesquisa e que se relacionam ao uso e aplicação de práticas de GC a partir de seu contexto profissional. Não se pretendeu analisar as práticas da instituição em que o estudo foi realizado, servindo esta apenas como campo de pesquisa para formação da amostra.

\section{APRESENTAÇÃO E DISCUSSÃO DOS RESULTADOS}

Através desta pesquisa buscou-se analisar de que forma a gestão do conhecimento está presente e contribui para o sucesso das instituições que atuam na modalidade Ead. Para tanto, procurou-se conhecer as concepções e práticas de coordenadores de curso 
acerca dos benefícios que as práticas voltadas à GC podem promover no cenário em que atuam.

$\mathrm{Na}$ área da educação, instituições privadas devem ter como compromisso a busca do equilíbrio entre a gestão voltada para a qualidade da educação ofertada e a gestão voltada para fins lucrativos. Especialmente no Brasil, em que a maioria das instituições que ofertam cursos na modalidade $\mathrm{EaD}$ são representadas por sistemas educacionais privados, a educação de qualidade deve ser o caminho para superar os desafios impostos pela competitividade do mercado educacional em expansão.

Os profissionais participantes da pesquisa, por atuarem em uma universidade privada, vivenciam a experiência de ver a qualidade do trabalho realizado refletida na imagem da instituição e acreditam que a gestão dos conhecimentos produzidos pelos profissionais contribui para que essa qualidade seja majorada. Um dos coordenadores entrevistados acredita que "a partir do momento em que as práticas de GC proporcionam aumento na qualidade do serviço prestado, os benefícios são revertidos para a instituição e para os alunos".

Para os coordenadores, através do compartilhamento de experiências, práticas e conhecimentos é possível aprimorar os processos e garantir mais qualidade na oferta do ensino. Nesse sentido, a GC contribui para que as instituições tenham mais competitividade no mercado em que atuam, conseguindo com que novos alunos tenham interesse em cursar os cursos ofertados, além de garantir a manutenção dos alunos que já estão matriculados, diminuindo a evasão.

De acordo com os participantes da pesquisa, as práticas de GC refletem em benefícios diretos para a instituição, para os profissionais envolvidos e para os alunos. De acordo com um dos entrevistados, "professores que são estimulados a compartilhar conhecimentos e experiências, discutindo temas atuais, têm condições de oferecer melhor qualidade de ensino".

É consenso entre os coordenadores que ao praticar a GC, as instituições podem dar voz ao que o ser humano tem de mais importante que é o seu conhecimento, e com isso garantir diferenciais de competitividade.

$\mathrm{Na}$ concepção de um dos coordenadores entrevistados, "quando o professor é ouvido e sente que a sua contribuição é valorizada pela instituição, ele desenvolve melhor o seu trabalho". A satisfação do professor se reflete na qualidade do ensino para o aluno, trazendo benefícios para a universidade, pois "um aluno satisfeito fala bem das suas 
experiências ao longo da sua formação e é a melhor propaganda que uma instituição pode ter".

Os coordenadores também destacaram a importância das tecnologias para atender as demandas educacionais da $\mathrm{EaD}$, bem como para gerir o conhecimento que circula de diferentes maneiras nesse cenário.

De modo geral, para os coordenadores, a EaD está intimamente relacionada às TIC. A aplicação das TIC nas práticas de GC, além de favorecer a conexão entre as pessoas e tornar disponíveis fontes de conhecimento, auxilia no gerenciamento, disseminação, compartilhamento e armazenamento de informações e conhecimentos.

Segundo os coordenadores, as características da EaD contribuem para uma cultura voltada para a inovação, que se inicia a partir do compartilhamento de informações e conhecimentos e envolve vários atores. Para os coordenadores, as metodologias da EaD não só estimulam, mas exigem muito a utilização das tecnologias.

Um dos exemplos citados foi a Biblioteca Digital, que permite a comunidade acadêmica acessar um grande volume de conhecimento estruturado. Através da Biblioteca Digital, todas as teleaulas e livros didáticos ficam disponíveis, contribuindo para ampliar a disseminação do conhecimento produzido. Além disso, as discussões promovidas entre docentes, tutores e alunos nos fóruns e chats em tempo real permitem aprender, construir e compartilhar conhecimentos. Cada vez mais as tecnologias educacionais tornam possível que a $\mathrm{EaD}$ ofereça uma rica variedade de componentes e recursos que permitem trabalhar com o conhecimento de forma mais efetiva.

O perfil dos profissionais que atuam na EaD também foi destacado pelos coordenadores. Segundo um dos entrevistados, "é preciso ter uma postura flexível e aberta para as inovações e mudanças que acontecem constantemente nesse cenário e que envolvem o uso de novas tecnologias e melhorias contínuas nos modelos educacionais. Nesse sentido, o perfil do professor que atua em EaD, pelo seu dinamismo e flexibilidade, contribui para o sucesso das práticas de GC".

Os depoimentos dos coordenadores acerca das contribuições que a GC pode prestar para a EaD permitem perceber que há clareza por parte dos profissionais a respeito da importância do compartilhamento e da valorização do conhecimento para o sucesso das atividades desenvolvidas em EaD. Os coordenadores confirmam a presença de ações voltadas para a GC, visando condições que possibilitem que os profissionais que atuam em EaD possam contribuir para a competitividade dos sistemas educacionais que 
utilizam a modalidade a distância na oferta de cursos de graduação superior.

Dentre uma relação de dez práticas e ferramentas voltadas para o compartilhamento do conhecimento, selecionadas a partir da literatura, os profissionais indicaram aquelas que utilizam para o desenvolvimento das suas atividades.

Para os coordenadores, a ferramenta mais utilizada é o espaço virtual colaborativo, com $100 \%$ de reconhecimento pelos profissionais, e que segundo Alarcon e Spanhol (2015), permite que as pessoas trabalhem em colaboração, compartilhando documentos, realizando edição colaborativa em coautoria, áudio e vídeo conferência, independentemente de onde estejam localizados. As lições aprendidas e a educação corporativa foram indicadas por $83,3 \%$ dos coordenadores, sinalizando que estas práticas colaboram para o desenvolvimento das suas atividades.

As práticas menos selecionadas pelos coordenadores, ainda que com índice mediano de utilização, foram as narrativas, a memória organizacional, os fóruns de discussão e o localizador de especialistas, todos com 50\% de indicações, conforme gráfico 1.

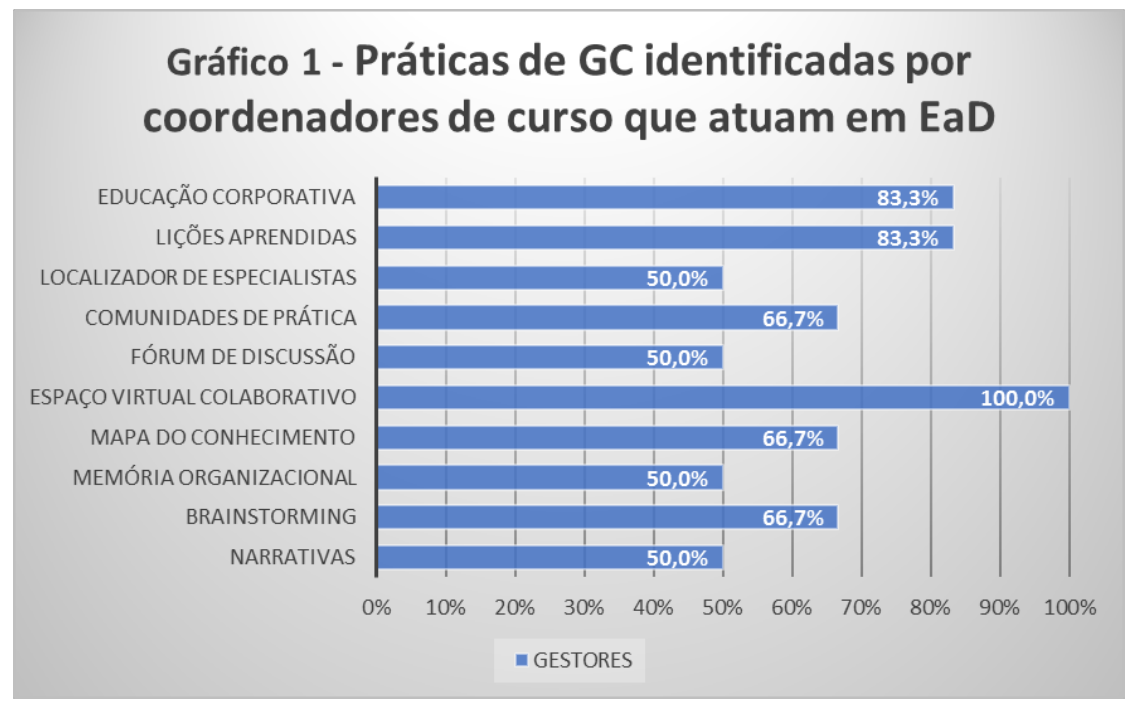

Fonte: Elaborado pela autora (2018).

Outra questão aplicada aos coordenadores diz respeito a percepção desses profissionais com relação às práticas de gestão do conhecimento, visando identificar de que forma a GC é percebida no ambiente profissional.

Foi possível verificar que para os coordenadores, processos que envolvem a GC estão presentes. Dois dos entrevistados acreditam que as práticas ainda acontecem de modo informal, mas identificam a preocupação de que sejam implementadas (33,3\%). Os 
demais profissionais $(66,7 \%)$ identificam a prática de maneira formalizada.

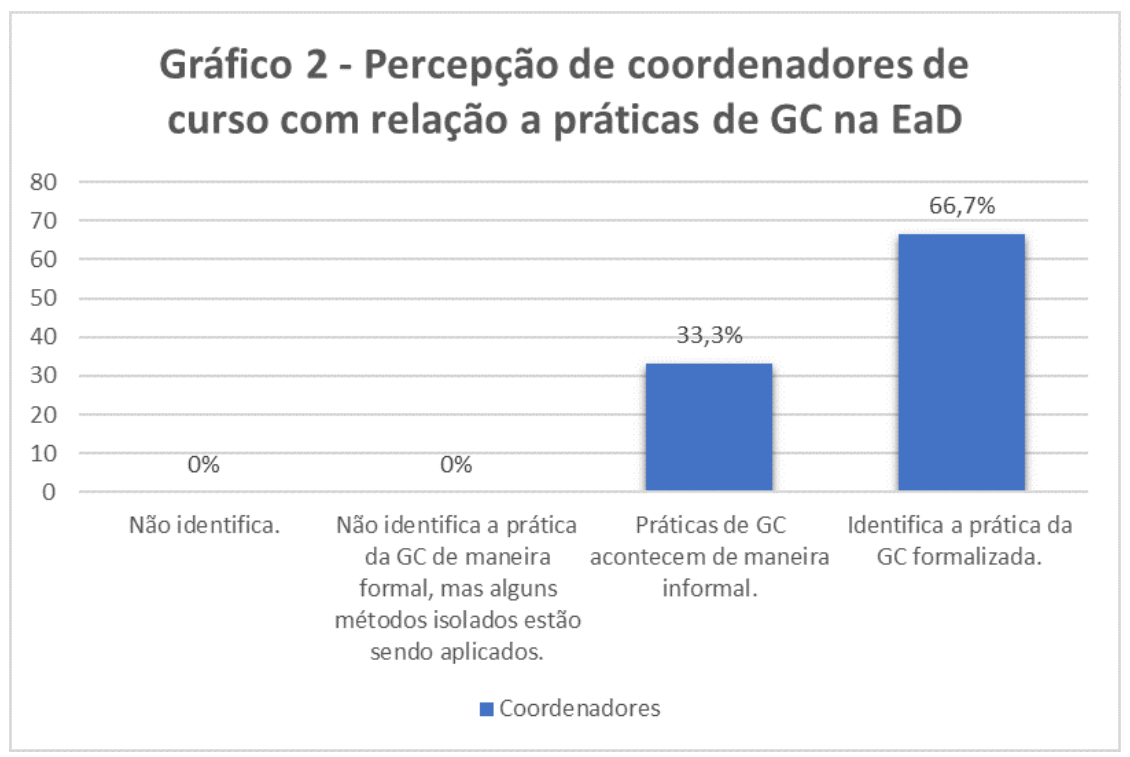

Fonte: Elaborado pela autora (2018).

Com base dos depoimentos colhidos foi possível conhecer algumas concepções e práticas de GC de coordenadores que atuam na modalidade EaD. Ações descritas pelos coordenadores permitem evidenciar experiências em relação as práticas de GC, além da presença de comportamentos que sinalizam a participação dos profissionais nessas práticas em atuação na EaD.

Com base dos depoimentos colhidos foi possível conhecer algumas concepções e práticas de GC de coordenadores que atuam na modalidade EaD. Ações descritas pelos coordenadores permitem evidenciar experiências em relação as práticas de GC, além da presença de comportamentos que sinalizam a participação dos profissionais nessas práticas em atuação na EaD.

\section{CONSIDERAÇÕES FINAIS}

Os relatos colhidos permitiram identificar a participação dos profissionais nos processos de gestão do conhecimento e identificar métodos de GC sendo utilizados para desenvolvimento das atividades em educação a distância.

Os profissionais demostraram ter clareza de que as práticas de GC proporcionam aumento na qualidade do serviço prestado, gerando benefícios, tanto para as instituições quanto para os alunos.

$\mathrm{Na}$ concepção dos participantes da pesquisa, a valorização do conhecimento e a 
presença das TIC são pontos fundamentais para que as práticas de GC sejam aplicadas com efetividade, garantindo melhor desempenho para os profissionais, alunos e instituições que atuam na modalidade EaD.

Apesar das constatações, há um longo caminho a percorrer. A cultura organizacional das instituições precisa estar em sintonia com as demandas atuais de uma sociedade em que a valorização do conhecimento é essencial. As universidades são importantes instituições nesse cenário, onde é possível encontrar um grande volume de informações e conhecimentos, visando a produção científica e a formação profissional e, justamente por esta razão, é preciso que as concepções e práticas voltadas a GC estejam presentes de maneira consciente e ativa através dos profissionais que nelas atuam.

\section{REFERÊNCIAS}

ALARCON, Dafne Fonseca; SPANHOL, Fernando José. Gestão do conhecimento na educação a distância: práticas para o sucesso. São Paulo: Pimenta Cultural, 2015.

BARBOSA, Ricardo Rodrigues. Gestão da informação e do conhecimento: origens, polêmicas e perspectivas. Informação \& Informação, v. 13, n. esp., p. 1-25, 2008.

DOROW, Patrícia Fernanda. Compreensão do compartilhamento do conhecimento em atividades intensivas em conhecimento em organizações de diagnóstico por imagem. 2017. 361 f. Tese (Doutorado em Engenharia e Gestão do Conhecimento). Universidade Federal de Santa Catarina, Florianópolis, 2017.

MATTERA, Tayane Cristina. Gestão do Conhecimento na prática. In: SOUTO, Leonardo Fernandes (Org.). Gestão da informação e do conhecimento: práticas e reflexões. Rio de Janeiro: Interciência, 2014, p. 199-220.

MORAES, Dinorá de Fátima Gonçalves. A educação a distância e a formação docente. 2016. Dissertação (Mestrado em Tecnologias, Comunicação e Educação). Universidade Federal de Uberlândia - Faculdade de Educação. Uberlândia, 2016.

NONAKA, Ikujiro; TAKEUCHI, Hirotaka. Criação do conhecimento na empresa: como as empresas geram a dinâmica da inovação. 2. ed. Rio de Janeiro: Campus, 1997. 